\title{
A general planner to explore drenching strategies in natural and organic lamb production systems
}

\author{
V.O. SNOW ${ }^{1}$, M.D. ROLLO ${ }^{2}$, S.J. LOVATT ${ }^{2}$, and R.A. DYNES ${ }^{3}$ \\ ${ }^{1}$ AgResearch, Grasslands Research Centre, PB 11 008, Palmerston North \\ ${ }^{2}$ AgResearch, Ruakura Research Centre, PB 3123, Hamilton \\ ${ }^{3}$ AgResearch, Lincoln Research Centre, PO Box 60, Lincoln \\ val.snow@agresearch.co.nz
}

\begin{abstract}
The need for anthelmintic drenching varies from animal to animal. To avoid unnecessary use of drenches it is therefore desirable to formulate drenching rules that apply to the individual, rather than the mob. We used a computer decision support tool called the general planner for agro-ecosystem models (GPAM) to investigate drenching rules for lamb production on a dual organic-conventional farm. The GPAM was combined with a dynamic model of nematode infection in lambs to help understand how varying premiums for organically produced lamb affected optimal drenching decisions. Simulations showed that there was no incentive to produce lambs organically if the premium for organic meat was less than $20 \%$. Even when the premium was increased to $80 \%$, half the lambs slaughtered had conventional status. As the premium increased, more lambs were produced organically and there was greater variation in liveweight between animals, whether drenched or undrenched. This modelling exercise demonstrated that there is potential to devise individualised drenching strategies that return the greatest carcass value for the entire mob. However, it is also clear that without alternative non-anthelmintic strategies to control infection, a significant proportion of the flock will have to be finished using drenches even with high premiums for organic lamb.
\end{abstract}

Keywords: organic lamb production, nematode infection, decision making, artificial intelligence

\section{Introduction}

All farmers are being encouraged to drench lambs according to demonstrated need rather than to a prescribed schedule (Meat \& Wool New Zealand 2006). The reasons for this are primarily associated with delaying the development of drench resistance, but also follow from a desire to use fewer chemicals in animal production and to reduce the costs. Using drenches only when needed is particularly important for natural and organic production systems because the carcass of a drenched lamb will not attract an organic premium (BIO-GRO New Zealand 2001). Drenching also has farm management implications because drenched lambs cannot return to the organic unit. Within organic production systems, management is a complex balance between animal welfare, lamb growth rate, and retaining the organic status of the lambs. There is a much greater expression of variation between individual animals under organic production systems compared to conventional systems (Mackay et al. 2006). This makes managing individuals, rather than the mob, more important.

In a parallel organic-conventional farm system, the farm is divided into organic and conventional areas known as platforms. It is assumed that the lambs all start on the organic platform and any lambs that are drenched are transferred to the conventional platform. To most efficiently manage these parallel platforms, managers must make decisions about which individual lambs to drench. Formulating measures and rules for drenching that can be applied to individuals, rather than the mob, raises several issues related to the trade-off between the greater return per unit weight from an undrenched lamb carcass and the possible heavier carcass from drenched lambs. For example, if the drenching rules are based on faecal egg count or weight change then what trigger values should be used? Should those trigger values be the same under all conditions or should they be conditioned by environmental variables, or perhaps other attributes of the individual or mob? At present organically-produced meat attracts a premium of between 10 and $20 \%$ compared to conventionally-produced meat. How might trigger values change to reflect changes in the market premium for organic lamb, or to likely seasonal changes in the schedule?

Rigorous field-based research of the multitude of possible management options under no- and low-drench management would be very lengthy and costly. Computer modelling is, however, a potential method to study drench management options. Therefore we developed a computer decision-making tool, called the general planner for agroecosystem models (GPAM), to help investigate management options and their consequences under noand low-drench regimes. This paper briefly describes the GPAM and how it was used with a dynamic model of nematode infection in lambs to gain a better understanding of how varying premiums for organically produced lamb might affect drenching decisions aimed 
at achieving the greatest value from the lamb carcass.

\section{Methods}

\section{The Nematode model}

In this study the GPAM was connected to the Nematode model of Louie et al. (2005, 2006, unpub. data), which simulates how animal immunity, worm burden, liveweight, and the level of nematode larval stage three (L3) contamination on the pasture evolve in response to nematode challenge. Thirty lambs, each with an individual level of resistance to parasites, are setstocked on a paddock where the pasture starts with a low level of infective L3 contamination. Initially, as the lambs grow their intake of pasture results in an increasing level of L3 intake. Because of each lamb's differing resistance to parasites (Louie et al. 2005), their worm burdens and immunity levels develop individually. The worm burden affects the lamb's appetite, and so liveweight gain also varies between lambs. The level of L3 concentration on the pasture develops from the combination of the eggs excreted from all the lambs grazing the pasture with removal of L3 through consumption by lambs and L3 death.

Minor changes were made to the implementation of the Nematode model in order to represent the parallel organic-conventional system. The model was not designed to have the number of lambs varying within the simulation run so the conventional platform was accommodated in the simulation by retaining drenched lambs in the simulation but their L3 intake was reduced by a factor of two in order to mimic the effect of a likely lower L3 concentration on the pasture of the conventional platform (B. Devantier, pers comm.). In addition, the drenched, conventional lambs did not add to the L3 contamination of the pasture on the organic platform.

\section{The General Planner for agro-ecosystem models}

A classic approach to solving planning or management problems using artificial intelligence is to construct a decision tree that predicts the consequences of all possible sequences of choices from the present time until some pre-defined finishing time (Russell \& Norvig 2003). Each leaf of the decision tree then represents a final state of the system. The values of the variables defining that state indicate how "good" a given state is. The best decision at any point in time can then be selected as the one that leads to the best outcome for the system.

The GPAM was set-up with rules about how frequently it can make and implement decisions, a list of alternative decisions it can make, and a model (in this instance Nematode) with which to predict the outcomes of those decisions. The GPAM then builds a decision tree of all the possible choices and searches the tree to find the best sequence of choices to optimise the outcome. In this case, the "goodness" measure used by the GPAM was the total carcass value of all lambs from a parallel organicconventional system under different levels of premium for the organically produced lamb. The total carcass value was calculated while various levels of organic premium ( 0 to $100 \%$ ) were applied to lambs that had never been drenched. For the calculation of carcass value we assumed that lambs less than $24 \mathrm{~kg}$ liveweight had no value and when a lamb reached $38 \mathrm{~kg}$ liveweight it was assumed to be slaughtered and removed from the simulation. No carcass grading was applied, premiums were held constant throughout the year, and the costs of drenching were not included.

The GPAM made choices at 4-week intervals from 18 weeks of age. The GPAM was instructed to find a 'trigger' value of liveweight gain below which lambs would be drenched. That trigger value was expressed as a percentage liveweight gain over a 4-week period $\left(\mathrm{G}_{\mathrm{P} 4}\right)$ and lambs that failed to meet the $\mathrm{G}_{\mathrm{P} 4}$ would be drenched and moved to the conventional platform. The $\mathrm{G}_{\mathrm{P} 4}$ was initialised at $0 \%$ when the lambs were 14 weeks old (4 weeks before the first possible drenching time) and was allowed to vary $0,1,2$, or 5 percentage points up or down at each 4-week interval.

Premiums for organic lamb ranging between $0 \%$ and $100 \%$ (steps of $5 \%$ ) were supplied, and the GPAM was instructed to decide on appropriate drenching rules for the parallel organic-conventional system. For comparative purposes, several organic premiums greater than $100 \%$ were tested as was lamb growth under no drenching and routine drenching of all animals every 4 weeks from weaning.

\section{Results and Discussion}

There was no financial incentive to produce organic lamb at premiums below $20 \%$ (Fig. 1). As the premium increased above $20 \%$, the reduction in carcass weight of undrenched animals was offset by the higher value per $\mathrm{kg}$ for organic animals. The percentage of animals with organic status at slaughter reached a plateau of $50 \%$ once the organic premium increased above $80 \%$. The results are consistent with the farmlet data reported by Mackay et al. (2006) reported in this issue. Premiums up to $400 \%$ showed the same behaviour as seen at $100 \%$ premium (data not shown) because many lambs did not reach the minimum slaughter weight.

The trigger value of liveweight gain for drenching, derived from the trigger $\mathrm{G}_{\mathrm{P} 4}$ values, fell into clearly defined groups (Fig. 2). At premiums below 20\%, trigger values were high, meaning that only the animals that grew quite quickly remained undrenched, and all animals were drenched before slaughter (Fig. 1). In this group, the premium for an organic carcass was too low to 
Figure 1 Percentage of lambs produced organically under varying organic premiums.

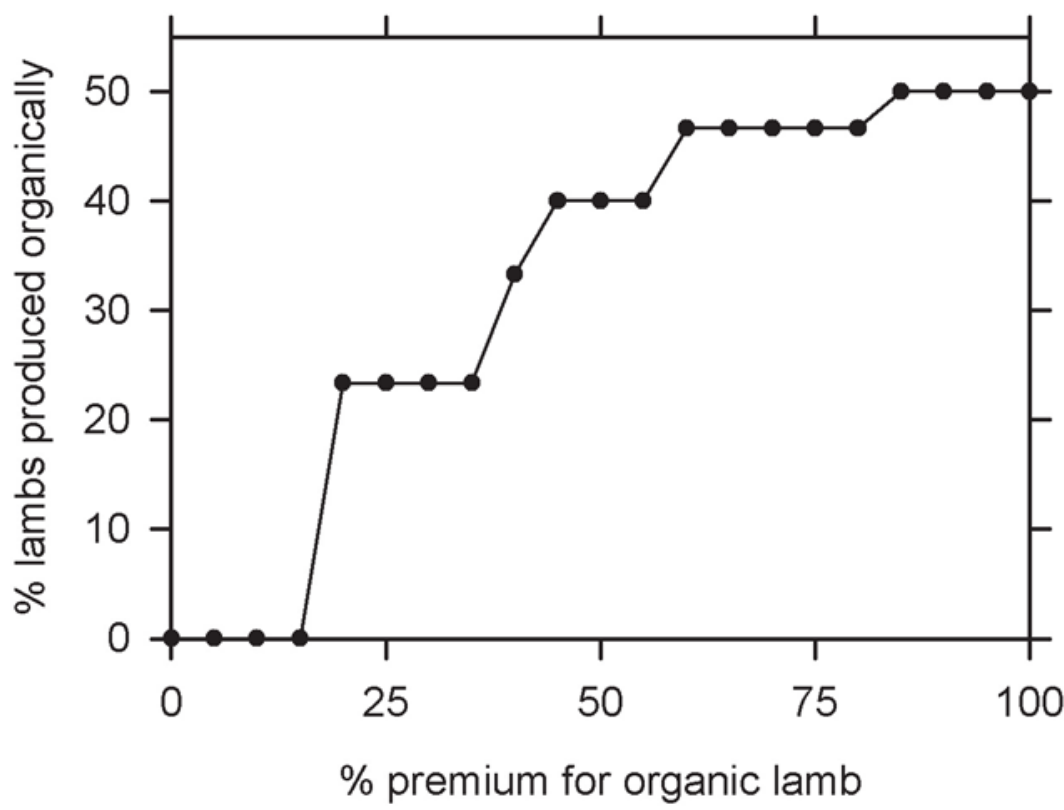

Figure 2 Trigger liveweight gain for three categories of organic premium.

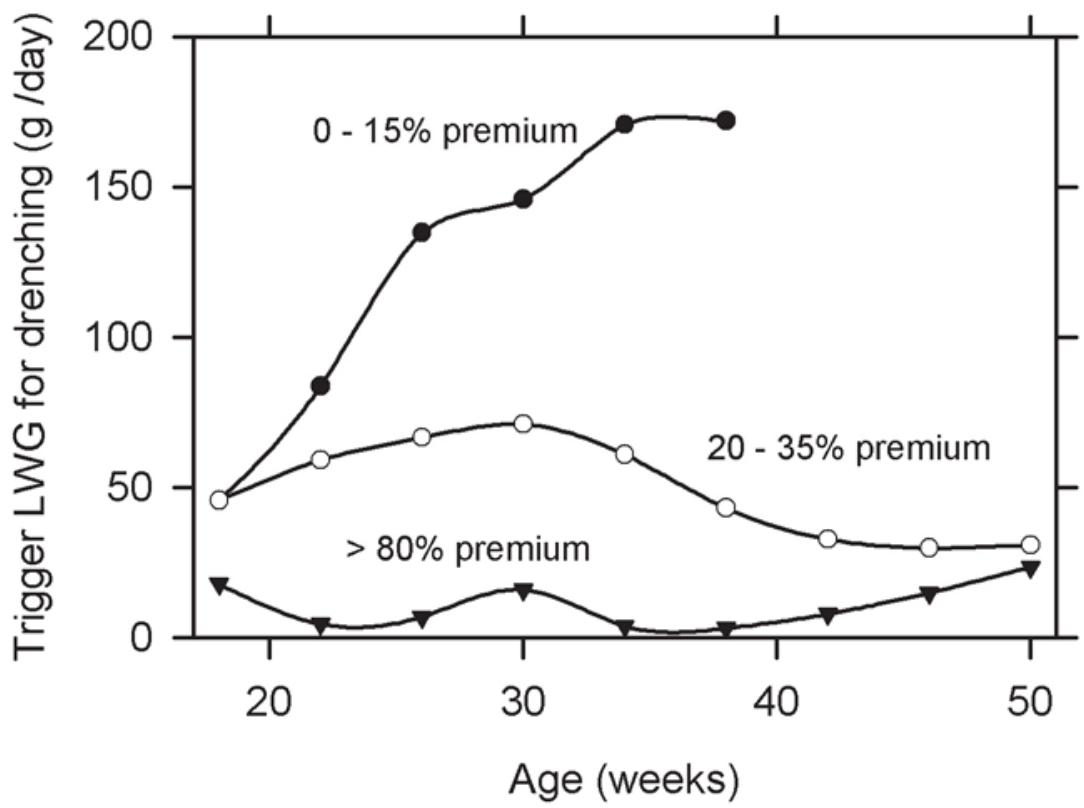

compensate for the reduced growth of undrenched animals. A clear change in behaviour occurred as the organic premium increased above $20 \%$ with the trigger $\mathrm{G}_{\mathrm{P} 4}$ dropping to lower values, meaning that fewer animals were drenched.

As the organic premium increased and fewer animals were drenched, there was a corresponding increase in the range of lamb liveweights at any point in time and in the average time taken to reach a $38 \mathrm{~kg}$ slaughter weight (Fig. 3). The higher within-flock variability in organic systems compared to conventional (all lambs drenched) demonstrates why the ability to manage individuals, and the timeliness of decisions is important in organic production systems. At higher premiums, there is greater variability in the liveweight of drenched animals because it is financially sensible to leave the lambs that are more 
Figure 3 Lamb liveweight for three categories of organic premium. Black lines indicate the weight of lambs that have not yet been drenched and grey lines show post-drenching weight. Also shown are lamb liveweights when all lambs were drenched every 4 weeks and when lambs were never drenched.

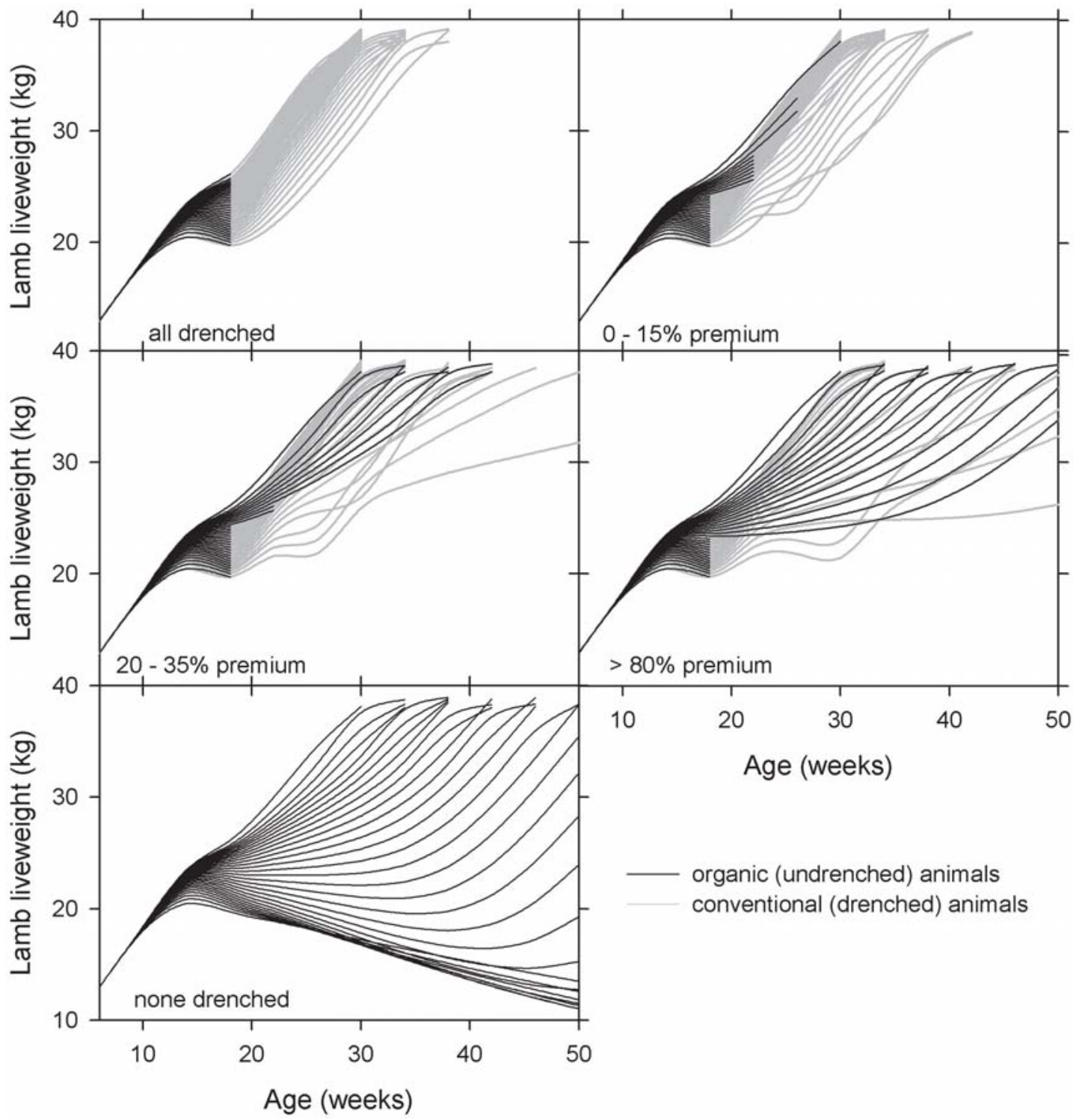

susceptible to the parasites undrenched.

Regardless of the increase in premium for organic meat above $80 \%$, the GPAM could not find benefit, in terms of carcass value, in producing more than $50 \%$ of the animals organically because the lambs did not reach slaughter weight within a year. This suggests that if a parallel platform is not available, successful organic production will depend on farming animals that are genetically more resistant to worm burden, the ability to provide clean pastures to animals or other methods consistent with organic specifications that reduce the effects of the high worm burdens.
The potential for using grazing strategies to manipulate L3 intake and nematode infection (Louie et al. 2006) and weaning age (Dynes et al. 2006) as reported elsewhere in this proceedings, demonstrate potential ways of addressing the challenges facing the production of organic sheep meat. Other work has shown that natural remedies have little potential for reducing the effects of nematode infection in lambs (Devantier 2004). We feel greater emphasis should be placed on breeding for resistance and developing grazing management options to manipulate L3 intake and provide clean pasture and crops for the more vulnerable young stock. 
The large variation in liveweight of organic lambs in Figure 3 suggests that, without the ability to provide clean forage, a significant proportion of lambs are likely to need drenching before slaughter just for animal welfare reasons. Given this, there is a clear role for dual-platform production systems and this, combined with breeding and pasture management, is likely to provide the best avenues for organic lamb production. Currently, organic premiums will need to increase to achieve significant conversions to organic lamb finishing systems.

\section{Conclusions}

There is potential to devise drenching strategies that return the greatest carcass values to farmers based on the organic premium. However it is clear that, without alternative strategies to control infection, a significant proportion of the flock will require drenching and be finished on a conventional platform even under high premiums for organic lamb. Breeding for resistance to nematode infection and grazing management to manipulate L3 intake, will be essential to allow producers to bring a significant proportion of their flock to slaughter weight with an organic specification.

Sophisticated simulation and decision-modelling approaches can be helpful in devising such strategies and it is likely that they will be important to ensure the success of organic farming options. As well as providing general guidelines, the simulation and decision-modelling techniques used in this paper are likely to be valuable in customising strategies of this sort to the requirements of individual farm systems.

\section{ACKNOWLEDGEMENTS}

The authors would like to thank: Ken Louie for provision of the Nematode model and assistance with implementation; Alec Mackay, Vicki Burggraaf, Alex
Vlassoff, Brian Devantier, and Chris Boom for valuable discussion and contributions. This work was funded under FRST contract C10X0236 "Natural and Organic".

\section{REFERENCES}

BIO-GRO New Zealand 2001. BIO-GRO New Zealand Organic Standards. BIO-GRO New Zealand.

Devantier, B.P. 2004. Evidence for the effectiveness of therapeutic remedies acceptable for the management of internal parasites of sheep and cattle in organic farming systems: A critical review. A paper presented in partial fulfilment of the requirements for a Graduate Diploma of Rural Studies. Massey University, New Zealand. $61 \mathrm{pp}$.

Dynes, R.A.; Moss, R.A.; Bray, A.R.; McAnulty, R.W. 2006. Effect of weaning age on growth rates of lambs infected by gastrointestinal parasites. Proceedings of the New Zealand Grasslands Association 68: XXX$\mathrm{XXX}$.

Louie, K.; Vlassoff, A.; Mackay, A. 2005. Nematode parasites of sheep: extension of a simple model to include host variability. Parasitology 130: 437-446.

Louie, K.; Vlassoff, A.; Boom, C.J.; Burggraaf, V.T. 2006. Modelling liveweight performance in parasitised grazing lambs. Proceedings of the New Zealand Grasslands Association 68: XXX-XXX.

Mackay, A.D.; Devantier, B.P.; Pomroy, W.E. 2006. Long-term changes in farm system behaviour associated with the shift to organic supply. Proceedings of the New Zealand Grasslands Association 68: XXXXXX.

Meat \& Wool New Zealand 2006. M\&WNZ R\&D Brief $115 \mathrm{Feb} 2006$.

Russell, S.J.; Norvig, P. 2003. Artificial Intelligence-A Modern Approach, 2nd Ed. Prentice-Hall, Upper Saddle River, NJ. 1132 pp. 